\title{
Serum prolactin in liver disease and its relationship to gynaecomastia
}

\author{
MARSHA Y. MORGAN, A. W. JAKOBOVITS, MARION B. R. GORE, M. R. WILLS, \\ AND SHEILA SHERLOCK
}

From the Departments of Medicine and Chemical Pathology, Royal Free Hospital, London

SUMMARY Serum immunoreactive prolactin was measured in 150 patients with liver disease of varying aetiology and severity and in 45 control subjects. The upper limit of the reference range for serum prolactin was $331 \mathrm{mU} / 1$. Eighteen patients with liver disease (12\%) had unexplained hyperprolactinaemia. No relationship existed between the prolactin value and the sex of the patient, the aetiology of the liver disease, the severity of the liver disease, or the presence of gynaecomastia. The cause of the hyperprolactinaemia in patients with liver disease and its clinical implications need further investigation.

Feminisation can occur in men with chronic liver disease and also in male alcoholics with only minimal liver damage (Kyrle, 1909; Corda, 1925; Silvestrini, 1926; Riebler, 1936; Glass et al., 1940; Lloyd and Williams, 1948; Summerskill et al., 1960; Van Thiel and Lester, 1974). Disturbances in endocrine function in women with chronic liver disease and in women alcoholics are poorly documented.

No single explanation for the endocrine changes in these patients has been found as so many factors appear to be involved. Alcohol abuse, drug treatment, and the nature and severity of the underlying liver lesion may all play a part and should therefore be taken into account.

Recently, it has been suggested that the pituitary polypeptide hormone prolactin might play a role in the endocrine changes of chronic liver disease. There has been debate as to whether raised concentrations of this hormone may be related to the gynaecomastia that can occur in male alcoholics and male patients with chronic liver disease (Turkington, 1972; Van Thiel et al., 1975; Van Thiel and Lester, 1976; Wernze and Schmitz, 1977).

We have therefore studied 150 patients with liver disease to find the incidence of hyperprolactinaemia and its correlation, if any, with the sex of the patient, the aetiology and severity of the liver lesion, and the presence of gynaecomastia.

\section{Methods}

SUBJECTS

The subject group comprised 150 patients, 78 (58

Received for publication 29 September 1977 males, 20 females) with alcohol related liver disease and 72 (26 males, 46 females) with non-alcohol related liver disease. The non-alcoholic group comprised primary biliary cirrhosis (24 patients), HBsAg negative chronic active hepatitis (18), cryptogenic cirrhosis (14), haemochromatosis (four), HBsAg positive liver disease (three), and miscellaneous liver disorders (13). The aetiology and severity of the liver disease was determined from clinical features, biochemical and serological tests, and liver histology. A particular note was made of any drug treatment.

The age and sex matched control group of 45 subjects comprised 15 healthy laboratory staff and 30 ward patients with either uncomplicated skin disease (20) or general medical disorders not known to be associated with endocrine abnormalities (10). None of the control subjects had abnormal liver function tests, was an alcoholic, or was taking drugs known to raise serum prolactin values (MacLeod, 1976).

Male patients and controls were examined by two independent observers for the presence of gynaecomastia, which was defined as the presence of a concentric subareolar mass with the consistency of breast tissue. An attempt was made to obtain breast secretion by firm manual expression.

Blood samples were drawn between 1400-1700 hours using a single puncture technique. Both subject and control groups of patients had been resting for at least one hour beforehand, and had no prior warning of the venepuncture. Serum was separated immediately and stored at $-20^{\circ} \mathrm{C}$ until assayed. Serum prolactin was measured using a double antibody technique (Cole and Boyns, 1973). The 
standard used was the MRC standard 71/222 containing 10 milliunits of prolactin per ampoule. The antiprolactin antiserum was kindly supplied by the Tenovus Institute, Cardiff. The samples for this study were assayed in two batches. The within assay coefficients of variation were $5.8 \%$ and $6.6 \%$ and the between assay coefficient of variation was $5.8 \%$. Statistical analyses were carried out using the unpaired $t$ test, the $2 \times 2 \chi^{2}$ test, and the Fisher exact probability test.

\section{Results}

The mean serum prolactin in the control group was $183 \pm 74 \mathrm{mU} / \mathrm{l}$ (ISD) and did not differ significantly between males $(178 \pm 73 \mathrm{mU} / \mathrm{l})$ and females $(190 \pm$ $78 \mathrm{mU} / \mathrm{l})$. The upper limit of this reference range (331 mU/l) was taken from the mean value for the whole group +2 SD. Patients with serum prolactin

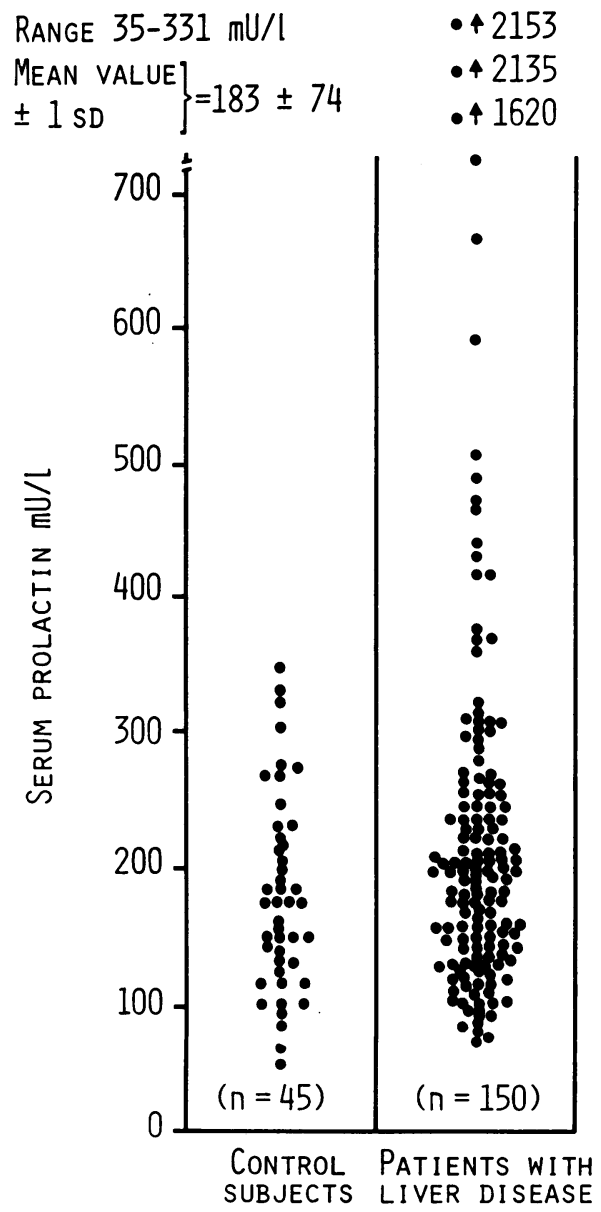

Fig. 1 Serum prolactin values in 150 patients with liver disease and 45 control subjects. values greater than this were considered to have hyperprolactinaemia. None of the 150 patients with liver disease was taking drugs known to raise the serum prolactin value (MacLeod, 1976). However 18 $(12 \%)$ were found to have hyperprolactinaemia (Fig. 1). The incidence of hyperprolactinaemia in the alcoholic group $13 \%(10 / 78)$, was similar to that in the non-alcoholic group $11 \%(8 / 72)$ (Table). The incidence of hyperprolactinaemia in the male and female patients did not differ significantly.

Table Incidence of hyperprolactinaemia in male and female patients with alcoholic and non-alcoholic liver disease

\begin{tabular}{|c|c|c|c|c|c|c|}
\hline & \multicolumn{2}{|c|}{$\begin{array}{l}\text { Whole group } \\
\text { (150) }\end{array}$} & \multicolumn{2}{|c|}{$\begin{array}{l}\text { Alcoholics } \\
\text { (78) }\end{array}$} & \multicolumn{2}{|c|}{$\begin{array}{l}\text { Non-alcoholics } \\
\text { (72) }\end{array}$} \\
\hline & (no.) & $(\%)$ & (no.) & $(\%)$ & (no.) & $(\%)$ \\
\hline $\begin{array}{l}\text { All patients with } \\
\text { hyperprolactinaemia } \\
\text { Males }\end{array}$ & $\begin{array}{l}18 \\
84\end{array}$ & 12 & $\begin{array}{l}10 \\
57\end{array}$ & 13 & $\begin{array}{r}8 \\
27\end{array}$ & 11 \\
\hline $\begin{array}{l}\text { With hyperpro- } \\
\text { lactinaemia } \\
\text { Females } \\
\text { With hyperpro- } \\
\text { lactinaemia }\end{array}$ & $\begin{array}{r}7 \\
66\end{array}$ & 17 & $\begin{array}{r}5 \\
21\end{array}$ & 24 & $\begin{array}{r}2 \\
45\end{array}$ & 13 \\
\hline
\end{tabular}

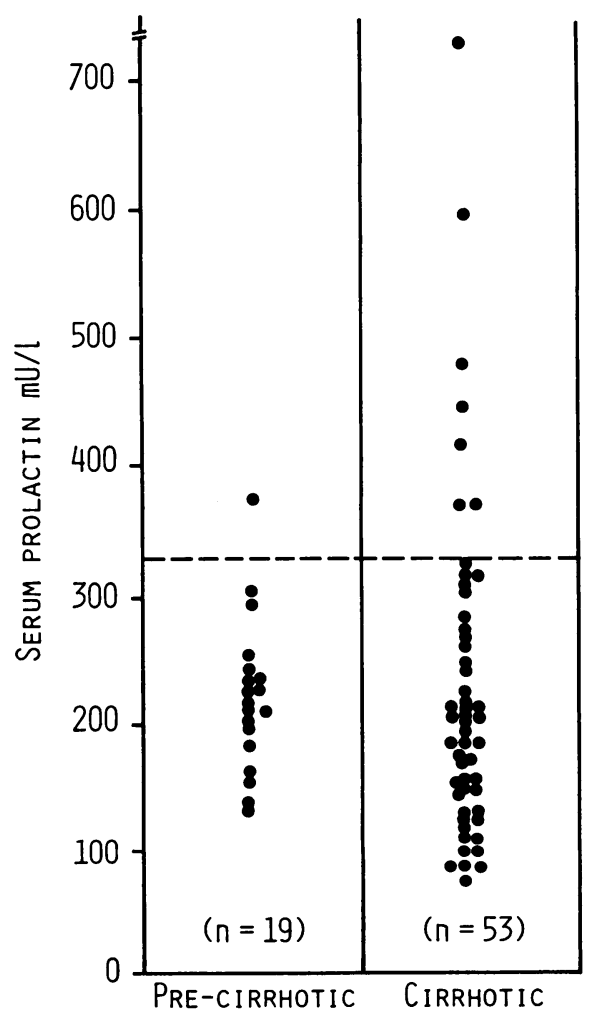

Fig. 2 Serum prolactin values in patients with non-alcohol related liver disease. 
Of the 72 patients with non-alcohol related liver disease, 19 had a precirrhotic liver lesion and 53 had cirrhosis. The incidence of hyperprolactinaemia in the patients with precirrhotic liver damage $(5 \%$; $1 / 19$ ) did not differ significantly from that in the patients with cirrhosis $(13 \% ; 7 / 53)$ (Fig. 2).

Of the 78 patients with alcohol related liver disease 23 had fatty change, 19 had alcoholic hepatitis, and 36 had cirrhosis. The incidence of hyperprolactinaemia in the patients with fatty change was $4 \%(1 / 23)$ compared with an incidence of $16 \%(9 / 55)$ in the patients with alcoholic hepatitis or cirrhosis, the more severe forms of alcohol related liver injury. This difference was not significant (Fig. 3).

Nineteen $(22.5 \%)$ of the 84 patients with liver disease had gynaecomastia, four of whom were taking $200 \mathrm{mg}$ spironolactone daily. The incidence of gynaecomastia in the alcoholic male $(24.6 \%$; $14 / 57)$ was similar to that in the non alcoholic males $(18.6 \% ; 5 / 27)$. No relationship was found between

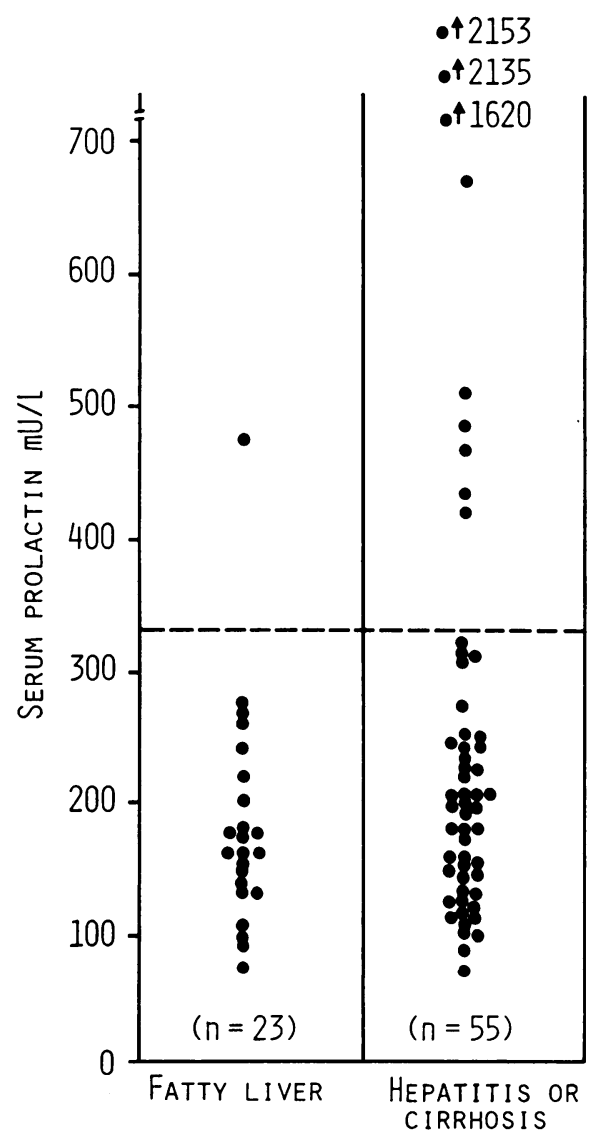

Fig. 3 Serum prolactin values in patients with alcohol related liver disease.

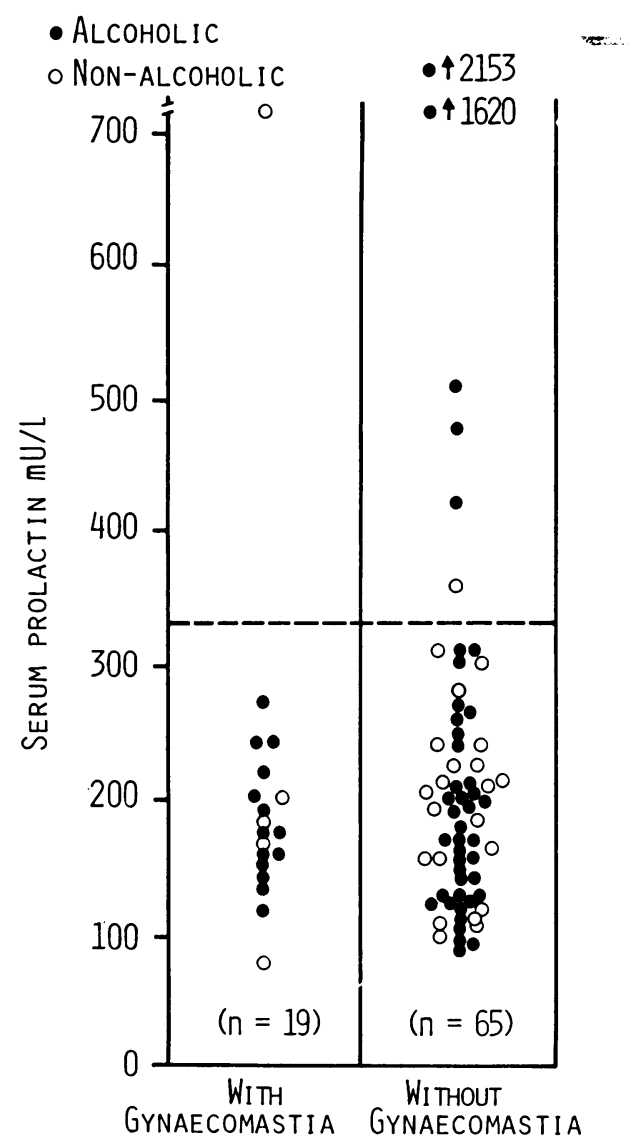

Fig. 4 Serum prolactin values in male patients with liver disease with and without gynaecomastia.

the serum prolactin concentration and the presence of gynaecomastia (Fig. 4). Firm manual expression failed to produce breast secretion in any of the male subjects.

\section{Discussion}

Serum prolactin has been shown to rise in response to an increase in circulating oestrogen concentration (Yen et al., 1974; Wiedemann et al., 1976). Many workers have reported changes in circulating concentrations of oestrogens in males with chronic liver disease (Glass et al., 1940; Adlercreutz, 1974; Green et al., 1976) and changes in serum prolactin values may be secondary to disturbances in oestrogen metabolism. Prolactin secretion might also be affected by a direct influence of alcohol on hypothalamic-pituitary function (Van Thiel et al., 1974; Van Thiel and Lester, 1976), although Toro et al. (1973), reported that prolactin levels do not increase 
in normal men and women after ingestion of alcohol.

In our series of 150 patients with liver disease, $18(12 \%)$ had raised serum prolactin concentrations which could not be attributed to known endocrine disease or to drug therapy. Van Thiel et al. (1975) and Van Thiel and Lester (1976) have reported raised prolactin levels in male alcoholics with liver disease, but the actual number of patients with an increase in prolactin was small and there was considerable overlap between the values seen in the control subjects and the patient group. Wernze and Schmitz (1977) found hyperprolactinaemia in $39 \%$ (29/75) of a group of patients with cirrhosis of various aetiologies.

We found no correlation between the incidence of hyperprolactinaemia and the aetiology of the liver disease, which conflicts with the findings of Wernze and Schmitz (1977). These workers reported raised prolactin values in $11.1 \%(3 / 27)$ of patients with non-alcoholic cirrhosis and in $54.2 \%(26 / 48)$ of patients with alcoholic cirrhosis.

Similarly, we found no significant correlation between the incidence of hyperprolactinaemia and the severity of the liver disease. Van Thiel et al. (1975) measured serum prolactin values in 50 male alcoholics with varying degrees of alcohol related liver disease, but did not comment on any relationship between prolactin value and severity of liver damage.

In our male patients, there was no relationship between the serum prolactin concentration and the presence of gynaecomastia. This confirms earlier work by Turkington (1972) who used a bioassay to measure prolactin in a group of patients with gynaecomastia of various aetiologies, including several with cirrhosis. Similarly Wernze and Schmitz (1977), using a radioimmunoassay, found no correlation between plasma prolactin values and the presence of gynaecomastia. Van Thiel et al. (1975), also using a radioimmunoassay, measured prolactin values in a group of alcoholic men and found higher values in those with gynaecomastia. In that series no clear indication was given, however, of the degree of liver damage, if any, in the patients studied.

In this study a raised serum immunoreactive concentration of prolactin was found in $12 \%$ of patients with liver disease. We have as yet no evidence that this contributes to the feminisation in male patients or that patients are in any way at a clinical disadvantage if their serum prolactin is raised. With all hormone assays, including prolactin, there is frequent and well-recognised dissociation between immuno- and bioactivity. The finding of normal serum immuno-reactive values using one particular antiserum does not exclude the presence of an increase in biologically active hormone which is not apparent because of the characteristics of the antiserum used.
This may, in part, account for the differences in results reported by previous authors and is the subject of a further study.

We wish to thank Mr M. Sabur of the Department of Chemical Pathology at The Royal Free Hospital for undertaking the prolactin assay.

\section{References}

Adlercreutz, H. (1974). Hepatic metabolism of estrogens in health and disease. New England Journal of Medicine, 290, 1081-1083.

Cole, E. N., and Boyns, A. R. (1973). Radioimmunoassay for human pituitary prolactin, using antiserum against an extract of human amniotic fluid. Hormone Research, 4, 261-273.

Corda, L. (1925). Scilla c.d. reviviscenza della mammella maschile nella cirrosi epatica. Minerva Medica (Torino), 5, 1067-1069.

Glass, S. J., Edmondson, H. A., and Soll, S. N. (1940). Sex hormone changes associated with liver disease. Endocrino$\log y, 27,749-752$.

Green, J. R. B., Mowat, N. A. G., Fisher, R. A., and Anderson, D. C. (1976). Plasma oestrogens in men with chronic liver disease. Gut, 17, 426-430.

Kyrle, J. (1909). Uber Strukturanomalien im menschlichen Hodenparenchym. Verhandlungen der Deutschen Gesellschaft für Pathologie, 13, 391-395.

Lloyd, C. W., and Williams, R. H. (1948). Endocrine changes associated with Laennec's cirrhosis of the liver. American Journal of Medicine, 4, 315-330.

MacLeod, R. M. (1976). Regulation of prolactin secretion. In Frontiers in Neuroendocrinology, Vol. 4, p. 169. Edited by L. Martini and W. F. Ganong. Raven Press: New York.

Riebler, R. (1936). Ueber einen Fall von Gynäkomastie und Leberzirrhose. Wiener Klinische Wochenschrift, 49, 1076-1077.

Silvestrini, R. (1926). La reviviscenza mammaria nell'uomo affetto da cirrosi del Laennec. Riforma Medica, 42, 701-704

Summerskill, W. H. J., Davidson, C. S., Dible, J. H., Mallory, G. K., Sherlock, S., Turner, M. D., and Wolfe, S. J. (1960). Cirrhosis of the liver: a study of alcoholic and nonalcoholic patients in Boston and London. New England Journal of Medicine, 262, 1-9.

Toro, G., Kolodny, R. C., Jacobs, L. S., Masters, W. H., and Daughaday, W. H. (1973). Failure of alcohol to alter pituitary and target organ homone levels. Clinical Research, 21, 505 (abs.).

Turkington, R. W. (1972). Serum prolactin levels in patients with gynaecomastia. Journal of Clinical Endocrinology and Metabolism, 34, 62-66.

Van Thiel, D. H., Gavaler, J. S., Lester, R., Loriaux, D. L., and Braunstein, G. D. (1975). Plasma estrone, prolactin, neurophysin, and sex steroid-binding globulin in chronic alcoholic men. Metabolism, 24, 1015-1019.

Van Thiel, D. H., and Lester, R. (1974). Sex and alcohol. New England Journal of Medicine, 291, 251-253.

Van Thiel, D. H., and Lester, R. (1976). Alcoholism: its effect on hypothalamic pituitary gonodal function. Gastroenterology, 71, 318-327.

Van Thiel, D. H., Lester, R., and Sherins, R. J. (1974). Hypogonadism in alcoholic liver disease: evidence for a double defect. Gastroenterology, 67, 1188-1199.

Wernze, H., and Schmitz, E. (1977). Plasma prolactin and prolactin release in liver cirrhosis. Acta Hepato-gastroenterologica, 24, 97-101.

Wiedemann, E., Schwartz, E., and Frantz, A. G. (1976). 
Acute and chronic estrogen effects upon serum somatomedin activity, growth hormone, and prolactin in man. Journal of Clinical Endocrinology, 42, 942-952.
Yen, S. S. C., Ehara, Y., and Siler, T. M. (1974). Augmentation of prolactin secretion by estrogen in hypogonada women. Journal of Clinical Investigation, 53, 652-655. 